\title{
Mi patria es el lenguaje
}

Resumen: Para la autora, el lenguaje abarca mucho más que un repertorio de palabras o un sistema de signos para comunicarnos. Es, como dice en este discurso leído en el contexto de su ingreso a la Academia Salvadoreña de la Lengua, el espacio en el que habitamos. Si es justo decir que percibimos el mundo a través de los sentidos, es igualmente acertado considerar que la realidad llega a nuestra mente filtrada, teñida y tamizada por la lengua. Esa creación nuestra que a su vez nos da a luz todos los días. La creamos y nos crea. Existimos en ella y ella vive en nosotros.

Abstract: According to the author, language embraces more than a mere asortment of word or a system of signs in order to communicate with each other. It is the space in which we dwell, as she states in this speech delivered when she became a member of the Salvadoran Academy of Language. If it is fair to say that we perceive the world through our senses, it is also right to consider that reality comes into our mind filtered, dyed and sifted through the language. That creation of ours, which in turn enlighten us every single day. We create it and it creates us. We exist in it and it lives in us.

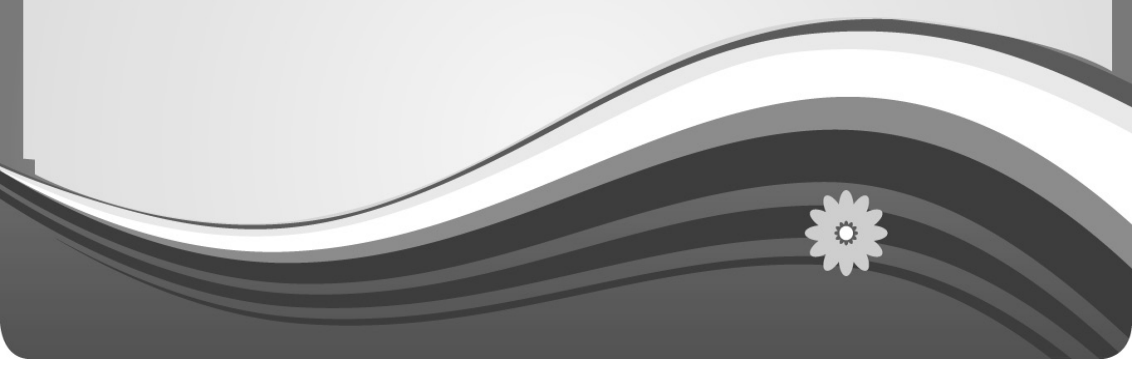

eñor Director, señor Rector, señoras y señores académicos, amigos todos:

Quiero agradecer, antes que nada, a la Academia Salvadoreña de la Lengua, que en su generosidad ha decidido acogerme como miembro de tan ilustre institución, y en especial a la doctora Irma Lanzas, que me hará el honor de responder a este discurso.

Dedico mis palabras a la memoria de mis padres, y a la de mis maestros, Víctor Santos y Francisco 
Andrés Escobar. Los cuatro profesaron un profundo amor al castellano y son la razón de que yo me encuentre aquí. Y también al Colegio Sagrado Corazón y a la UCA, ya que debo a estas dos instituciones mi educación básica y media y mi formación universitaria.

¿Quién podría decirnos, tantos siglos después, el nombre del oscuro funcionario cuya mano escribió el original del más antiguo de los Cartularios de Valpuesta? En medio de las líneas latinas, según algunos, muy corrompidas o evolucionadas, escritas en esa localidad a unos cien kilómetros de la ciudad de Burgos, se percibe la presencia de las primeras palabras de una lengua que se hablaba ya por los caminos polvorientos de Castilla y de León allá por el año 800.

Aquella lengua incipiente, que otro monje anónimo usó, alrededor del año 1000, para dejar una anotación al margen del libro santo que estudiaba, anotaciones que hoy conocemos como las Glosas Emilianenses, también fue el vehículo del que se valieron las autoras de unas cancioncillas que hoy conocemos como jarchas hispanoárabes, para contar sus cuitas de amor.

Aquellas voces lejanas día a día se alejaban más del latín vulgar que llegó a la península ibérica a cabaIlo junto con las legiones romanas, y que al poner pie a tierra se les desprendían a los soldados de las cáligas, de las capas y de los gladios, aquellas espadas de doble filo de cuyo nombre deriva la palabra gladiola, sembrando el idioma, injertándolo y fertilizándolo con una manera distinta de ver el mundo.

Una lengua no es un conjunto de palabras. No es ni siquiera la estructura gramatical que dichas palabras configuran y a la que se adscriben para dar lugar a la significación. Tampoco se limita la lengua a ser el principal sistema de símbolos con que contamos los seres humanos: Es todo eso. Pero también es mucho más. Si es justo decir que percibimos el mundo a través de los sentidos, es igualmente acertado considerar que la realidad Ilega a nuestra mente filtrada, teñida y tamizada por la lengua. Esa creación nuestra que a su vez nos da a luz todos los días. La creamos y nos crea. Es a la vez nuestra madre y nuestra hija. Existimos en ella y ella vive en nosotros.

Hay realidades que podemos pensar y decir en griego, en sueco o en suajili, pero no contamos en castellano, en cada caso, con palabras que las traduzcan exactamente. De modo que es justo decir que hay trozos de realidad que existen cabalmente solo en algunas lenguas.

Hay significaciones que, como ciertas herencias, son intransferibles. Cada lengua tiene voces con matices, registros y acepciones sin una estricta correspondencia 
término a término con los de otra. Siempre hay diferencias, sutiles o de bulto. $Y$ aun dentro del mismo castellano: "can" no equivale exactamente a "perro", y menos a "lebrel". Cada uno de estos vocablos tiene matices propios, únicos. Ahí radica el inmenso poder de un idioma: El poder de evocar, de dar cuenta y de transmitir emoción, pensamiento y experiencia vital. El poder de dibujar con distintos colores, de iluminar y describir cada parcela de la realidad.

Por eso, probablemente, es que casi siempre los vencedores imponen su lengua a los vencidos. Nada hay que nos dé unas señas de identidad y nos entregue el mundo como las palabras con las que pensamos y vivimos. Nada que nos encarcele y nos libere como la palabra. Y nada, también, tan inasible como los variados contenidos irracionales que viajan pegados a cada una como ineludibles rémoras.

Puente y muro, lazo o botella lanzada al mar cargada de esperanzas, la palabra es mucho más que un medio de comunicación, con todo y ser la más importante herramienta con la que contamos para dar a conocer nuestras ideas, nuestras emociones y todo el bagaje de experiencia humana que hemos acumulado a través de los años.

Las personas no vivimos tan solo en un tiempo y en un espacio determinados. Ante todo, vivimos sumergidas en una lengua. En ella amamos, reímos, sufrimos y soñamos. Es en ese ámbito, sonoro y escrito, donde concretamos todas las incidencias de nuestra historia. En una lengua determinada y concreta hacemos planes, escribimos versos de amor, redactamos cartas, Ilenamos formularios, firmamos contratos, votamos en las elecciones, juramos cargos, reflexionamos, investigamos, sacamos conclusiones, construimos conocimientos, asentamos a nuestros hijos y les damos una identidad vital y jurídica de la que difícilmente podrían gozar sin el lenguaje.

Cómo será de importante la lengua que ella misma crea realidad. Con ella escribimos la historia. Damos fe de batallas y de luchas, de victorias y derrotas. Tejemos afectos. Establecemos hechos. Formulamos hipótesis y teorías. Apuntalamos argumentos y juicios. Dejamos testimonio de nuestra andadura vital. Prefiguramos el futuro.

La Wikipedia nos dice que el castellano es la segunda lengua hablada como lengua materna, después del chino mandarín, por 432 millones de personas, además de otras que lo han aprendido como segunda o tercera lengua hasta completar 460 millones de hablantes.

El castellano o español es el segundo idioma más estudiado después del inglés, con 20 millones de 
estudiantes alrededor del mundo, 5 millones de ellos solo en Brasil, y la tercera con más usuarios de Internet, con 164 millones.

También es uno de los seis idiomas oficiales de la ONU, además de la lengua más hablada en 25 países y territorios, y en muchos de ellos es lengua oficial. En 2009 había más de 35 millones de hablantes del castellano solo en los Estados Unidos, donde es la lengua más hablada después del inglés. Para el año 2030, fuentes académicas han previsto que el castellano será la segunda lengua más hablada en el planeta.

Un día, hace mucho, cuando yo era muy niña, mi tío Federico Huguet visitó a su hermano, mi abuelo Antonio. De inmediato se pusieron a hablar en una lengua que no pude entender, aunque algunas palabras aisladas me sonaron conocidas. "¿Qué están haciendo?”, le pregunté a mi abuela María. "Están hablando en catalán", me contestó.

El descubrimiento personal de que existían otras lenguas en el mundo, es decir, que no todos los habitantes del globo hablaban castellano, fue uno de los hechos más sorprendentes a los que me he enfrentado en la vida. Estoy segura de que mi abuelo y mi tío no veían al mundo de la misma forma a través del catalán que a través del castellano.
Como me señaló un buen amigo hace algún tiempo: qué frío, o que tímido, suena ese "t'estimo" en catalán, aunque sea seguido del adverbio "encara", en la canción del cantautor Joan Manuel Serrat, nativo de Poble Sec, en Barcelona. Sobre todo si lo comparamos con el "te quiero" castellano, que se compromete del todo. Tal vez las lenguas sean, además de léxico y sintaxis, cuestión de carácter.

Hoy que mi familia anda repartida entre Australia, Estados Unidos, El Salvador y el otro lado del vasto Océano Atlántico, cuando las cenizas de mis padres reposan en California y mis hijos viven en Antiguo Cuscatlán, me suena cada vez más cierto aquello que dijera Albert Camus una vez: "Mi patria es la lengua francesa", que es casi idéntico a lo que ya había dicho Fernando Pessoa al afirmar: "Mi patria es la lengua portuguesa".

En 1994 algo semejante afirmó Herta Müller, escritora alemana que nació en Rumanía y recibió el Premio Nobel de Literatura en 2009 cuando dijo: "A fin de cuentas, mi patria no es la lengua, ni la española ni la francesa: mi patria es el lenguaje. O sea, un espacio de comunicación social, de invención lingüística; una posibilidad de representación del universo, de modificarlo también, aunque sea mínima o marginalmente, por el lenguaje mismo. Ahora bien, en esa patria mía que es el lenguaje, hay ideas, 
imágenes emblemáticas, momentos emocionales, resonancias intelectuales, cuyo origen es específicamente alemán. Me atrevería a decir que, en cierto modo, 'lo alemán' -en poesía, novela, reflexión filosófica- es un componente esencial de mi patria espiritual". Fin de la cita.

Humildemente, para mí también la lengua es la patria. No el catalán, que fue la patria en que mi abuelo materno siguió pensando a lo largo de los setenta años que vivió en El Salvador, ni el castellano de Valladolid, con todas sus ces, eses y zetas, del habla de mi padre, sino el castellano tan fuertemente nahuatizado de esta tierra que, tal vez, habrá de cobijarnos, incluso en medio de los asaltos del espánglish.

Porque en realidad yo vivo aquí en este lugar donde pronunciamos las eses tirando ligeramente a jotas, las ces como eses y donde nos empeñamos en construir perífrasis verbales del orden de: "voy a ir al cine", en lugar de usar simplemente la forma verbal "iré", cosa que nadie hace por estos pagos.

Mi patria es, pues, el castellano. Este castellano. Una patria viva, como un rosal o como un conacaste, a la que se le caen hojas muertas todos los días, pero que reverdece también todos los años con el aporte de nuevos vocablos que nacen en las bocas y mentes de sus hablantes, en todos los puntos cardinales de este sufrido y maltratado planeta a donde quiera que vaya a dar un inmigrante salvadoreño.

A veces da la impresión de que la lengua florece gracias a la labor de millares de pacientes jardineros embarcados en la tarea de investigar el léxico y de escribir diccionarios donde se despliegue su inaudita riqueza. Otros, parece que el idioma sobrevive a pesar de las sañudas insidias, por ignorancia o por maldad, de sus torturadores.

La lengua es esa casa donde todos vivimos, nos movemos, y en el caso de los escritores, escribimos. Tal vez por eso me duele tanto la grosería e indignidad con que la pisoteamos algunos, desde los creativos de la publicidad, los periodistas, los narradores deportivos, los presentadores de la televisión y, claro está, mis alumnos.

Nunca podrán entender lo que me duelen los horrores de ortografía con que me topo a diario en todas partes: en la calle, en los rótulos, en los exámenes, en el Facebook y hasta en las recetas de los medicamentos que me dan en el Seguro Social. Me duelen todos y cada uno de esos hojos con hache, yuvia con ye y con uve, awa con doble v... me parecen pedradas infligidas con saña en la más delicada vidriera de una catedral gótica. El grosero escarnio de un rebaño de bárbaros que no comprenden lo que destruyen. Un atentado contra la más hermosa herencia que tenemos el 
ำ deber de custodiar. Porque también, al fin y al cabo, la lengua es el mejor medio que hemos encontrado para poder entendernos.

Ya lo dijo, mejor que yo, el poeta:

¡Pues si esta casa es la Patria, tan firme que acaso tiemble, tan dulce que acaso ahogue, tan honda que acaso vuele!

Y yo nunca me iré de ella, aunque el huracán arrecie...
Porque los poetas, más que vivir de las palabras, vivimos en ellas, para ellas. Ellas son nuestro patrimonio. Nuestro porqué y nuestro cómo. No podemos dejarlas. Nunca nos abandonan. Viajan con nosotros. Son la mejor justificación, si hiciera falta, contra la muerte. La más pura razón para haber existido.

Muchas gracias. 